\title{
Sorbitol hydrogenolysis to glycols by supported ruthenium catalysts
}

\author{
Inmaculada Murillo Leo, Manuel Lopez Granados, Jose Luis Garcia Fierro, Rafael Mariscal* \\ Group of Sustainable Energy and Chemistry, Institute of Catalysis and Petrochemistry (CSIC), C/Marie Curie 2, Cantoblanco, 28049 Madrid, Spain
}

\section{A R T I C L E I N F O}

Article history:

Received 17 March 2014

Accepted 20 March 2014

Published 20 May 2014

\section{Keywords:}

Sorbitol

Glycols

Hydrogenolysis

Ruthenium

Oxide supports

\section{A B S T R A C T}

Supported Ru catalysts were prepared by wet impregnation to evaluate the role of different oxide supports $\left.\mathrm{Cl}_{2} \mathrm{O}_{3}, \mathrm{SiO}_{2}, \mathrm{TiO}_{2}, \mathrm{ZrO}_{2}\right)$ in sorbitol hydrogenolysis to glycols. X-ray diffraction, transmission electron microscopy, hydrogen chemisorption, X-ray photoelectron spectroscopy, and $\mathrm{NH}_{3}$ temperature-programmed desorption were used to characterize the catalysts, which were active in the hydrogenolysis of sorbitol. The support affected both the physicochemical properties and catalytic behavior of the supported $\mathrm{Ru}$ particles. The characterization results revealed that the $\mathrm{Ru} / \mathrm{Al}_{2} \mathrm{O}_{3}$ catalyst has a high surface acidity, partially oxidized Ru species on the surface, and a higher surface $\mathrm{Ru} / \mathrm{Al}$ atomic ratio, which gave it the highest selectivity and yield to glycols.

(C) 2014, Dalian Institute of Chemical Physics, Chinese Academy of Sciences. Published by Elsevier B.V. All rights reserved.

\section{Introduction}

Lignocellulosic biomass is an important raw material due to its abundance, availability, and renewable nature [1-3]. The lignocellulosic feedstock is composed of structural carbohydrates, cellulose $(38 \%-50 \%)$ and hemicelluloses (23\%-32\%), and aromatic polymer lignin (15\%-25\%) [4]. Cellulose is currently used in the paper, textile, and wood industries. Several catalytic processes are being developed to convert cellulose in a single step into high added value chemicals like sugars and alcohols like sorbitol or derived polyols with less carbon atoms [5-11]. Currently, sorbitol is industrially obtained by glucose hydrogenation with Raney Ni catalysts. Cellulose is hydrolyzed into glucose which in turn is reduced in the presence of a supported metal catalyst to sorbitol.

Sorbitol is one of the ten most relevant building blocks derived from biomass because many high added value products can be derived from it [12]. Among the possible reactions for sorbitol valorization, we focused here on the hydrogenolysis pathway to produce glycols, mainly 1,2-propylene (1,2-PG) and ethylene glycols (EG), which are both important commodities.
They are widely used as antifreeze, lubricants, hydraulic fluids, monomers for thermoplastics, and also in the pharmaceutical industry [13-16]. At the moment, 1,2-PG and EG are petrochemicals because they are produced by the hydrolysis of propylene oxide and ethylene oxide, respectively. Consequently, the hydrogenolysis of sorbitol is an interesting renewable alternative to produce these chemicals.

The hydrogenolysis of sorbitol starts with the dehydrogenation reaction to give aldose and ketoses followed by retro-aldol condensation, which is favored in basic medium, to yield carbonyl compunds like glyceraldehyde and glycolaldehyde. Hydrogenation of the latter results in the selective formation of glycols (1,2-PG and EG) [17]. Keenan et al. [18] reported that the retro-aldol mechanism was insufficient for explaining the product distribution, while the decarbonylation mechanism can explain the selectivity of the terminal C-C scission. Sorbitol hydrogenolysis requires the use of $\mathrm{Ni}$ or $\mathrm{Ru}$-based catalysts under high $\mathrm{H}_{2}$ pressure and the use of basic promoters. The selectivity to glycols increases with the presence of a basic promoter, but the problems of accelerated degradation and glycol product separation occur [16].

\footnotetext{
* Corresponding author. Tel: +34-91-5854938; Fax: +34-91-5854760; E-mail: r.mariscal@icp.csic.es DOI: 10.1016/S1872-2067(14)60086-3 | http://www.sciencedirect.com/science/journal/18722067 | Chin. J. Catal., Vol. 35, No. 5, May 2014
} 
Much research work reported to date on sorbitol hydrogenolisis has focused on the effect of the type of metal catalyst and reaction conditions on the catalytic behavior. Sohounlouse et al. [19] described in their pioneering work sorbitol hydrogenolysis with $\mathrm{Ru} / \mathrm{SiO}_{2}$ as the catalyst, and they reported an overall glycol selectivity of $50 \%$ at $483 \mathrm{~K}, 8.0 \mathrm{MPa}$ of $\mathrm{H}_{2}$ and $\mathrm{pH}=12.5$. In a neutral medium, the lowering of the temperature leads to an increase in selectivity giving mainly glycerol and 1,2-PG. Zhao et al. [20-22] reported a sorbitol conversion of $86 \%$ and selectivity of $51 \%$ for glycols and $9 \%$ glycerol at $493 \mathrm{~K}, 8.0 \mathrm{MPa}$ of $\mathrm{H}_{2}$ and $800 \mathrm{r} / \mathrm{min}$ after $4 \mathrm{~h}$ of reaction using carbon nanofiber supported Ru catalysts in the presence of a basic promotor (CaO). These authors also suggested that glycerol was the primary product and propylene glycol was derived from glycerol. Banu et al. [14,23] studied the catalytic properties of $\mathrm{Ru}(1 \%)$ and $\mathrm{Ni}(6 \%)$ supported on a basic zeolite $\mathrm{NaY}$ in the presence of $\mathrm{Ca}(\mathrm{OH})_{2}$ as a basic promoter. A nickel catalyst presented the highest selectivity to propylene glycol, $69 \%$ for a sorbitol conversion of $75 \%$ at $493 \mathrm{~K}, 6.0 \mathrm{MPa}$ of $\mathrm{H}_{2} 300 \mathrm{r} / \mathrm{min}$ after $6 \mathrm{~h}$ of reaction.

Sun et al. [13] studied xylitol hydrogenolysis reaction on supported $\mathrm{Ru}$ catalysts at $473 \mathrm{~K}$ and $4.0 \mathrm{MPa} \mathrm{H}_{2}$. These authors examined the effects of the support and basic promoter on the catalytic performance and obtained $20 \%$ xylitol conversion and a selectivity to glycols of $50 \%$ in the presence of a basic promoter $\mathrm{Ca}(\mathrm{OH})_{2}$. The activity and selectivity depended on the $\mathrm{H}_{2}$ pressure, reaction temperatures, and $\mathrm{pH}$. The addition of $\mathrm{Ce}$ into the $\mathrm{Ni} / \mathrm{Al}_{2} \mathrm{O}_{3}$ catalysts showed a remarkable promoting effect on the catalytic behavior of sorbitol hydrogenolysis to produce glycols [24]. A glycol selectivity higher than $40 \%$ for complete sorbitol conversion was reported at $493 \mathrm{~K}$ under 7.0 $\mathrm{MPa}$ of $\mathrm{H}_{2}$ and after $8 \mathrm{~h}$ of reaction in basic medium.

Recently, Soták et al. [25] reported yields to glycols of $46 \%$ and $71 \%$ for the hydrogenolysis of $20 \mathrm{ml}$ of $5 \mathrm{wt} \%$ aqueous solution of sorbitol and xylitol, respectively, at $473 \mathrm{~K}$ and 4.0 MPa in 45 min of reaction. These authors used high loadings of nickel phosphides supported on active carbon as catalyst $(0.2$ g) and a basic promoter $(0.25 \mathrm{~g}), \mathrm{Ba}(\mathrm{OH})_{2} \cdot 8 \mathrm{H}_{2} \mathrm{O}$ for adjusting the $\mathrm{pH}$ of the reaction. Chen et al. [16] have reported sorbitol hydrogenolysis without a basic promoter using coprecipitated $\mathrm{Ni} / \mathrm{MgO}$ catalysts. After $4 \mathrm{~h}$ of reaction at $473 \mathrm{~K}$ and $4.0 \mathrm{MPa} \mathrm{H}_{2}$, the best catalyst exhibited $68 \%$ sorbitol conversion and $60 \%$ selectivity to glycols. Deactivation occurred because $\mathrm{MgO}$ was partly solubilized by water.

Despite these investigations, the effect of the support on the catalytic properties has received much less attention.Thus, the aim of this work was to investigate the effect of the oxide support $\left(\mathrm{Al}_{2} \mathrm{O}_{3}, \mathrm{SiO}_{2}, \mathrm{TiO}_{2}, \mathrm{ZrO}_{2}\right)$ on the structure and physicochemical properties of supported $\mathrm{Ru}$ catalysts and their catalytic performance in sorbitol hydrogenolysis to glycols (1,2-PG and EG). The study was conducted in the absence of a basic promoter and under a low pressure of $\mathrm{H}_{2}(4.0 \mathrm{MPa})$. It is well known that these parameters are important for a good yield to glycols, but under our reaction conditions, the effect of the support would not be overshadowed by the presence of a basic promoter and high $\mathrm{H}_{2}$ pressure, and the effect of the support would be more visible and detectable.

\section{Experimental}

\subsection{Preparation of the catalysts}

A series of $5 \mathrm{wt} \%$ supported Ru catalysts was prepared by impregnation of an aqueous solution of $\mathrm{Ru}(\mathrm{NO})\left(\mathrm{NO}_{3}\right)_{3}$ (Alfa Aesar) on $\mathrm{Al}_{2} \mathrm{O}_{3}$ (209 m²/g), $\mathrm{SiO}_{2}\left(208 \mathrm{~m}^{2} / \mathrm{g}\right), \mathrm{TiO}_{2}\left(53 \mathrm{~m}^{2} / \mathrm{g}\right)$, and $\mathrm{ZrO}_{2}\left(39 \mathrm{~m}^{2} / \mathrm{g}\right.$ ) supports (Sigma-Aldrich). The solid obtained was dried at $383 \mathrm{~K}$ for $12 \mathrm{~h}$. Prior to use as catalyst, the dried solid was subjected to the following treatment: (1) calcination under a $20 \mathrm{vol} \% \mathrm{O}_{2} / \mathrm{Ar}$ flow $(100 \mathrm{~mL} / \mathrm{min})$ at $623 \mathrm{~K}$ (heating rate of $10 \mathrm{~K} / \mathrm{min}$ ) for $1 \mathrm{~h}$; (2) reduction in $5 \mathrm{vol} \%$ $\mathrm{H}_{2} /$ Ar flow (100 mL/min) at $473 \mathrm{~K}$ (heating rate of $5 \mathrm{~K} / \mathrm{min}$ ) for $0.5 \mathrm{~h}$. These temperatures were selected based on previous evolved gas analysis by mass spectrometry and temperature programmed reduction (TPR) experiments, respectively, that showed that these calcination and reduction procedures fully decomposed the precursor and reduced the Ru oxides formed in the calcination step. Metal oxides with an acidic or neutral nature were selected for this study. Basic oxides such as MgO would suffer leaching in the reaction [16].

\subsection{Characterization of the catalysts}

Evolved Gas Analysis by Mass Spectrometry (EGA-MS) was performed by loading the sample $(0.05 \mathrm{~g})$ in a U-shaped quartz reactor connected to a Balzer PrismaTM quadrupole mass spectrometer (QMS 200). The analysis was conducted while flowing a $20 \mathrm{vol} \% \mathrm{O}_{2} / \mathrm{Ar}$ mixture $(50 \mathrm{~mL} / \mathrm{min}$ ) from room temperature to $1000 \mathrm{~K}$ at a heating rate of $10 \mathrm{~K} / \mathrm{min}$. The fragments $m / z=18\left(\mathrm{H}_{2} \mathrm{O}^{+}\right), m / z=30\left(\mathrm{NO}^{+}\right), m / z=40\left(\mathrm{Ar}^{+}\right)$, $m / z=44\left(\mathrm{~N}_{2} \mathrm{O}^{+}\right)$, and $m / z=46\left(\mathrm{NO}_{2}{ }^{+}\right)$were continuously monitored with the mass spectrometer. Gas lines from the reactor to the MS inlet were heated at $393 \mathrm{~K}$ to avoid $\mathrm{H}_{2} \mathrm{O}$ condensation. TPR experiments were conducted in the same experimental set-up. A 5 vol $\% \mathrm{H}_{2} / \mathrm{Ar}$ mixture was flowed through the sample (ca. $0.1 \mathrm{~g}$ ) while heating from room temperature to $1000 \mathrm{~K}$ at a rate of $5 \mathrm{~K} / \mathrm{min}$. In this case, the fragments $m / z=2\left(\mathrm{H}_{2}{ }^{+}\right), m / z=$ $18\left(\mathrm{H}_{2} \mathrm{O}^{+}\right)$, and $m / z=40\left(\mathrm{Ar}^{+}\right)$were registered to evaluate the reduction process.

Powder X-ray diffraction (XRD) patterns were recorded at $2 \theta=10^{\circ}-90^{\circ}$ in the scan mode $\left(0.04^{\circ}, 20 \mathrm{~s}\right)$ using an $X^{\prime}$ Pert Pro PANalytical diffractometer with $\mathrm{Cu} K_{\alpha 1,2}(\lambda=0.15418 \mathrm{~nm})$ radiation. Diffractograms were analyzed with the X'Pert HighScore Plus software. The crystallite size (D) was calculated by the Scherrer equation.

A JEOL JEM-2100F transmission electron microscope (TEM) operated at $200 \mathrm{kV}$ (point resolution $0.19 \mathrm{~nm}$ ) was employed to conduct high resolution TEM analysis of the catalysts. The TEM was equipped with a EDAX Genesis detector. The catalytic precursors were calcined and reduced under the conditions detailed in the activation procedure. The reduced samples were transferred to the TEM without exposure to air.

$\mathrm{H}_{2}$ chemisorption was performed using a dynamic method. $0.1 \mathrm{~g}$ of reduced catalyst was loaded in a U-shaped quartz reactor connected to a Balzer PrismaTM quadrupole mass spectrometer (QMS 200). After an in situ activation procedure, the 
reactor was flushed with an Ar flow ( $50 \mathrm{~mL} / \mathrm{min}$ ) for $1 \mathrm{~h}$ at the same temperature, then the temperature was decreased and the catalyst was kept at $373 \mathrm{~K}$. Subsequently, a flow of 0.32 vol $\% \mathrm{H}_{2} / \mathrm{He} /$ Ar was passed through the sample bed. The $m / z=$ $40\left(\mathrm{Ar}^{+}\right)$and $m / z=4\left(\mathrm{He}^{+}\right)$signals increased rapidly while the $m / z=2\left(\mathrm{H}_{2}+\right)$ signal was delayed as a result of both $\mathrm{H}_{2}$ physisorption and chemisorption. Then, physisorbed $\mathrm{H}_{2}$ was removed by flowing Ar for 30 min. Finally, a second $\mathrm{H}_{2}$ adsorption experiment was performed to determine the amount of chemisorbed $\mathrm{H}_{2}$, which was calculated by subtracting one curve from the other and integration of the area obtained. Dispersion and particle size ( $\mathrm{dvA}_{\mathrm{A}}$ ) data were calculated assuming a stoichiometry $\mathrm{Ru} / \mathrm{H}$ of 2 . The average particle size was determined by the expression, $d_{\mathrm{VA}}=6 v_{\mathrm{m}} / D a_{\mathrm{m}}$, where $D$ is metal dispersion (the ratio of the surface metal atoms to the total number of metal atoms), $v_{\mathrm{m}}$ is the volume occupied by a metal atom $(1.364$ $10^{-2} \mathrm{~nm}^{3} /$ atom) in the bulk, and $a_{\mathrm{m}}$ is the surface area occupied by an surface metal atom (9.09 $10^{-2} \mathrm{~nm}^{2} /$ atom) [26-28]. The supports were also used as blank for all samples.

X-ray photoelectron spectra (XPS) were acquired with a VG Escalab 200R spectrometer equipped with a hemispherical electron analyzer and a $\mathrm{Mg} K_{\alpha}(h v=1253.6 \mathrm{eV})$ X-ray source. The reduced powder sample was rapidly placed into a flask containing isooctane to prevent sample oxidation by ambient air. Then, the solid was rapidly pressed into a copper holder mounted on a sample rod in the pretreatment chamber of the spectrometer to remove the protecting agent (isooctane). The solid was outgassed at room temperature for $1 \mathrm{~h}$ at $10^{-5} \mathrm{mbar}$ to remove isooctane before the transfer to the analysis chamber. $\mathrm{Ru} 3 d, \mathrm{Al} 2 p$, Si $2 p$, Ti $2 p, \mathrm{Zr} 3 d, \mathrm{C} 1 s$, and $01 s$ regions were scanned sufficient times to obtain high signal-to-noise ratios. The areas of the peaks were computed by fitting the experimental spectra to Gaussian/Lorenztian curves after removing the background using the Shirley function. Surface atom ratios were calculated from peak area ratios normalized by the corresponding atomic sensitivity factor [29].

The acidic properties of the catalysts were determined by temperature programmed desorption of ammonia ( $\left.\mathrm{NH}_{3}-\mathrm{TPD}\right)$. The reduced catalyst $(0.2 \mathrm{~g})$ was pretreated at $473 \mathrm{~K}$ for $0.5 \mathrm{~h}$ and then cooled to $373 \mathrm{~K}$ under $\operatorname{Ar}(50 \mathrm{~mL} / \mathrm{min})$. A flow of 5 vol\% $\mathrm{NH}_{3} / \mathrm{He}$ was passed through the sample bed for $0.5 \mathrm{~h}$ at $373 \mathrm{~K}$, and a subsequent flushing with Ar at the same temperature to remove the physisorbed ammonia was applied. $\mathrm{NH}_{3}$ desorption was carried out from room temperature to $1000 \mathrm{~K}$ with a heating rate of $10 \mathrm{~K} / \mathrm{min}$. TPD analysis was registered with a Balzer PrismaTM quadrupole mass spectrometer (QMS 200) by following the fragments $m / z=16\left(\mathrm{NH}_{2}{ }^{+}\right), m / z=17$ $\left(\mathrm{NH}_{3}{ }^{+}\right), m / z=18\left(\mathrm{H}_{2} \mathrm{O}^{+}\right), m / z=28\left(\mathrm{~N}_{2}{ }^{+}\right), m / z=30\left(\mathrm{NO}^{+}\right), m / z=$ $40\left(\mathrm{Ar}^{+}\right), m / z=44\left(\mathrm{~N}_{2} \mathrm{O}^{+}\right)$, and $m / z=46\left(\mathrm{NO}_{2}{ }^{+}\right)$to record the desorption of $\mathrm{NH}_{3}$ and to account for the oxidation of $\mathrm{NH}_{3}$ to nitrogen oxides. Quantitative determination of desorbed ammonia was based on the $m / z=16$ signal normalized to $m / z=$ 40 signal (Ar) by integrating the area under this desorption curve. The calibration of this signal was carried out by using streams with different $\mathrm{NH}_{3}$ concentration.
Sorbitol hydrogenolysis was carried out in a stainless steel autoclave Parr reactor $(100 \mathrm{~mL})$. In a typical experiment, $30 \mathrm{~g}$ of aqueous sorbitol solution (20 wt\% sorbitol) and $0.3 \mathrm{~g}$ of reduced catalyst ( $5 \mathrm{wt} \%$ relative to sorbitol) were loaded in the autoclave, which was then flushed several times with $\mathrm{N}_{2}$ and $\mathrm{H}_{2}$ to remove ambient air. Subsequently, the temperature was increased to $493 \mathrm{~K}$ and the $\mathrm{H}_{2}$ pressure adjusted to $4.0 \mathrm{MPa}$, which was kept unchanged during the reaction. Finally, the mixture was stirred at $500 \mathrm{r} / \mathrm{min}$ to start the reaction, which was conducted for $4 \mathrm{~h}$. The reactants and liquid products were analyzed by high performance liquid chromatography (HPLC) equipped with a Rezex RHM-Monosaccharide $\mathrm{H}^{+}(8 \%)(300 \times$ $7.80 \mathrm{~mm}$ ) column and refraction index (RI) and UV (DAD) detectors. Samples for the chromatographic analysis were prepared by adding a known amount of internal standard. $\mathrm{A}_{2} \mathrm{SO}_{4}$ ( $5 \mathrm{mmol} / \mathrm{L}, 0.45 \mathrm{~mL} / \mathrm{min}$ ) mobile phase was employed as eluent at $313 \mathrm{~K}$. Sorbitol conversion was defined as the ratio between the number of sorbitol moles consumed in the reaction and the number of sorbitol moles initially present in the mixture. The yield was defined as the ratio of the number of moles of product formed to the total moles of sorbitol initially present with taking into account the molar stoichiometry of the product. The selectivity was defined as the result of dividing the yield by the sorbitol conversion.

The total carbon balance in the liquid was measured with a total organic carbon analyzer TOC-V CSH of Shimadzu. This instrument measures the concentration of total carbon (TC) and inorganic carbon (IC). Total organic carbon (TOC) was calculated as the difference between these two values. To perform this analysis, $3 \mathrm{~mL}$ of solution was filtered with a Varian Captiva TM column with a pore diameter of $0.45 \mu \mathrm{m}$. $1 \mathrm{~mL}$ of the filtered sample was diluted in $100 \mathrm{~mL}$ of deionized water and an aliquot of this solution was injected into the analyzer.

\section{Results and discussion}

\subsection{Catalytic activity of supported Ru catalysts}

Table 1 summarizes the conversion and selectivity shown by the supported $\mathrm{Ru}$ catalysts, including a commercial $\mathrm{Ru} / \mathrm{Al}_{2} \mathrm{O}_{3}$ catalyst $\left(\mathrm{Ru} / \mathrm{Al}_{2} \mathrm{O}_{3}-\mathrm{c}\right)$ and a blank $\mathrm{Al}_{2} \mathrm{O}_{3}$ support. $\mathrm{A}$ reaction time of $4 \mathrm{~h}$ was selected based on kinetic experiments

Table 1

Catalytic activity of supported Ru catalysts in sorbitol hydrogenolysis.

\begin{tabular}{lcccccc}
\hline \multirow{2}{*}{ Catalyst } & \multirow{2}{*}{$X_{\text {sorbitol }}(\%)$} & \multicolumn{5}{c}{ Selectivity (\%) } \\
\cline { 3 - 7 } & & Glycols $^{\mathrm{a}}$ & $\mathrm{GLY}^{\mathrm{b}}$ & \multicolumn{1}{c}{$\mathrm{PA}^{\mathrm{c}}$} & $\mathrm{MA}^{\mathrm{d}}$ & $\mathrm{DP}$ \\
\hline $\mathrm{Al}_{2} \mathrm{O}_{3}$ & 15.7 & 0.0 & 0.0 & 100.0 & 0.0 & 0.0 \\
$\mathrm{Ru} / \mathrm{Al}_{2} \mathrm{O}_{3}$ & 73.9 & 19.1 & 6.5 & 6.8 & 4.9 & 1.2 \\
$\mathrm{Ru} / \mathrm{Al}_{2} \mathrm{O}_{3}-\mathrm{c}$ & 80.2 & 9.2 & 5.1 & 12.3 & 5.0 & 2.7 \\
$\mathrm{Ru} / \mathrm{SiO}_{2}$ & 96.1 & 4.9 & 2.1 & 14.6 & 3.2 & 1.9 \\
$\mathrm{Ru} / \mathrm{TiO}_{2}$ & 85.8 & 5.0 & 1.7 & 23.1 & 2.5 & 3.1 \\
$\mathrm{Ru} / \mathrm{ZrO}_{2}$ & 83.4 & 5.2 & 1.5 & 26.5 & 1.9 & 2.3 \\
\hline
\end{tabular}

Reaction conditions: sorbitol $6 \mathrm{~g}, \mathrm{H}_{2} \mathrm{O} 24 \mathrm{~g}$, catalyst $0.3 \mathrm{~g}, \mathrm{H}_{2} 4.0 \mathrm{MPa}$, $493 \mathrm{~K}, 4 \mathrm{~h}, 500 \mathrm{r} / \mathrm{min}$.

a 1,2-propanediol and ethylene glycol; b glycerol; ' polyalcohols: xylitol, ribitol, and erythriol; ${ }^{\mathrm{d}}$ monoalcohols: ethanol; ${ }^{\mathrm{e}}$ dehydration products: sorbitan and acetol. 
(results not shown) that observed the evolution of the reactants and products versus time. All the supported Ru catalysts gave higher than $70 \%$ sorbitol conversion. Ru supported on $\mathrm{SiO}_{2}$ showed the highest sorbitol conversion, followed by the catalyst on $\mathrm{TiO}_{2}$ and $\mathrm{ZrO}_{2}$ supports, with the least active being the supported $\mathrm{Al}_{2} \mathrm{O}_{3}$ catalyst. However, the $\mathrm{Ru} / \mathrm{Al}_{2} \mathrm{O}_{3}$ catalyst presented the best selectivity to glycols (19.1\%). A pure $\mathrm{Al}_{2} \mathrm{O}_{3}$ support gave $15.7 \%$ sorbitol conversion, and was completely selective to polyalcohols of five carbon atoms. This means that $\mathrm{Ru}$ was the selective species in the sorbitol transformation to glycols.

With respect to selectivity, it should be first noted that the distribution of products was very broad, and to simplify this, we have grouped the reaction products into glycols (1,2-PG and $\mathrm{EG}$ ), glycerol (GLY), polyalcohols (PA) including sugar alcohols with 4 or 5 carbon atoms as xylitol, ribitol, and erythritol, and monoalcohols (MA) such as ethanol and dehydration products (DP) such as sorbitan and acetol derived from sorbitol and glycerol. Table 1 shows that the $\mathrm{Ru} / \mathrm{Al}_{2} \mathrm{O}_{3}$ catalysts, both the commercial one and that prepared in our laboratory, gave higher selectivities to glycols and glycerol, and consequenlty higher yields than the other supported $\mathrm{Ru}$ catalysts tested. In contrast, the $\mathrm{Ru} / \mathrm{SiO}_{2}, \mathrm{Ru} / \mathrm{TiO}_{2}$, and $\mathrm{Ru} / \mathrm{ZrO}_{2}$ samples exhibited higher selectivity to polyalcohols (around 14\%-27\%). Low selectivity to monoalcohols and dehydration products were obtained for all the catalysts.

The wide distribution of products can be explained by the competition between the the $\mathrm{C}-\mathrm{C}$ and $\mathrm{C}-\mathrm{O}$ bond cleavage route to produce polyalcohols, glycols, glycerol and monoalcohols and the dehydration of sorbitol to sorbitan, which lead to the formation of isosorbide by a second dehydration reaction. Previous studies have reported the dehydration of sorbitol in water at a high temperature or in the presence of a solid acid catalyst under hydrogen pressure [30-32].

In general, these selectivity values were lower than those reported by other authors with supported $\mathrm{Ru}$ based catalyst $[13,14,18,20-22]$. However, it must be kept in mind that our reaction conditions were selected to highlight the effect of the support on sorbitol hydrogenolysis. The presence of other activity enhancing factors, in particular the $\mathrm{pH}$ of the medium and the $\mathrm{H}_{2}$ pressure, would have overshadowed the samller effect of the support. Also, since a fraction of the reaction products cannot be identified and quantified by liquid chromatography, the measurment of the total organic carbon (TOC) present in the liquid product was carried out. Around $20 \%$ of the carbon in the liquid product was not quantified in the HPLC analysis. Under our reaction conditions, some gas products were formed, which would be $\mathrm{C}_{1}$ compounds like methanol, $\mathrm{CH}_{4}$, and CO since polyalcohols $\mathrm{C}_{5}$ (xylitol and ribitol) were identified in the liquid phase.

In summary, $\mathrm{Ru} / \mathrm{Al}_{2} \mathrm{O}_{3}$ clearly gave a higher yield to glycols due to the significantly higher selectivity than the other catalysts tested.

\subsection{Characterization of the Ru catalysts}

The thermal decomposition of the ruthenium (III) nitrosyl nitrate precursor salt in air was followed by temperature programmed EGA-MS (results not shown). The aim was to determine the temperature required to form the $\mathrm{Ru}$ oxide. Fragments with $m / z=218,30,32,44$, and 46 were registered. Only signal $m / z=30$ corresponding to the $\mathrm{NO}^{+}$fragment was detected. All the samples exhibited a broad peak associated with the decomposition process in the range of 400-625 K. Therefore, all the catalytic precursors were treated in air at $623 \mathrm{~K}$ for $1 \mathrm{~h}$, which guaranteed the complete decomposition of the precursor salt to the oxide.

The reducibility properties of these calcined catalysts were studied by $\mathrm{H}_{2}$-TPR. This also allowed the determining of the required temperature to generate metallic $\mathrm{Ru}$ by the complete reduction of $\mathrm{Ru}$ oxide. Figure 1 depicts the $\mathrm{H}_{2}$ signal normalized to the weight of catalyst loaded into the reactor for each experiment. All the catalysts gave a $\mathrm{H}_{2}$ consumption peak with a maximum centered at $400-425 \mathrm{~K}$. The $\mathrm{Ru} / \mathrm{SiO}_{2}$ and $\mathrm{Ru} / \mathrm{TiO}_{2}$ catalysts gave a reduction peak at a slightly higher temperatures than the $\mathrm{Ru} / \mathrm{Al}_{2} \mathrm{O}_{3}$ and $\mathrm{Ru} / \mathrm{ZrO}_{2}$ catalysts. This peak was attributed to reduction of $\mathrm{Ru}$ ions in $\mathrm{RuO}_{x}$ to metallic $\mathrm{Ru}^{0}$ $[33,34]$. From these results, a reduction at $473 \mathrm{~K}$ for $0.5 \mathrm{~h}$ was selected (see dashed line in Fig. 1) to carry out the reduction of all samples.

The XRD patterns of the Ru catalysts are represented in Fig. 2. The $\mathrm{Ru} / \mathrm{SiO}_{2}$ and $\mathrm{Ru} / \mathrm{Al}_{2} \mathrm{O}_{3}$-c catalyst diffractograms have peaks associated with the $\mathrm{Ru}^{0}$ phase (JCPDS 6-0663) with reflections at $2 \theta=44.0^{\circ}, 38.4^{\circ}$, and $42.2^{\circ}$. For the other catalysts, these peaks were not observed. Although they may not have been detected due to overlapping by the more intense diffraction peaks from the support, the absence of these diffraction lines in these samples suggested that $\mathrm{Ru}$ was well dispersed and consequently have a small particle size (less than $5 \mathrm{~nm}$ ). Diffraction peaks associated with the $\mathrm{RuO}_{x}$ phase were not observed. The diffraction peaks in the $\mathrm{Ru} / \mathrm{Al}_{2} \mathrm{O}_{3}-\mathrm{C}, \mathrm{Ru} / \mathrm{ZrO}_{2}$, $\mathrm{Ru} / \mathrm{TiO}_{2}$, and $\mathrm{Ru} / \mathrm{Al}_{2} \mathrm{O}_{3}$ diffractograms were due to the oxide support in the catalyst. $\mathrm{Ru} / \mathrm{Al}_{2} \mathrm{O}_{3}$ showed peaks corresponding to the $\mathrm{Al}_{2} \mathrm{O}_{3}$ support (JCPDS 46-1131), $\mathrm{Ru} / \mathrm{TiO}_{2}$ presented mainly the peaks of $\mathrm{TiO}_{2}$ anatase (JCPDS 21-1272) and some $\mathrm{TiO}_{2}$ rutile phase (JCPDS 77-0442). The $\mathrm{Ru} / \mathrm{ZrO}_{2}$ diffractogram peaks corresponding to monoclinic (JCPDS 1-0750) and tetragonal $\mathrm{ZrO}_{2}$ (JCPDS 81-1546) were visible. The $\mathrm{Ru} / \mathrm{Al}_{2} \mathrm{O}_{3}-\mathrm{C}$

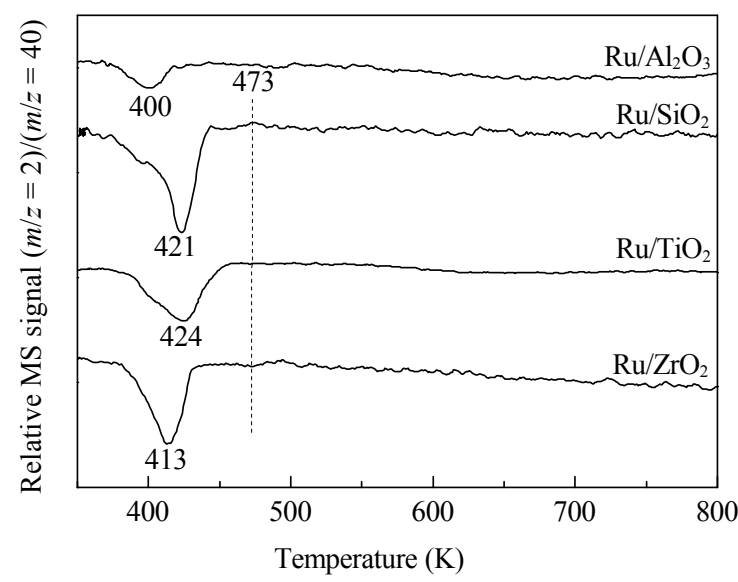

Fig. 1. $H_{2}$-TPR profiles of calcined supported Ru catalysts. 


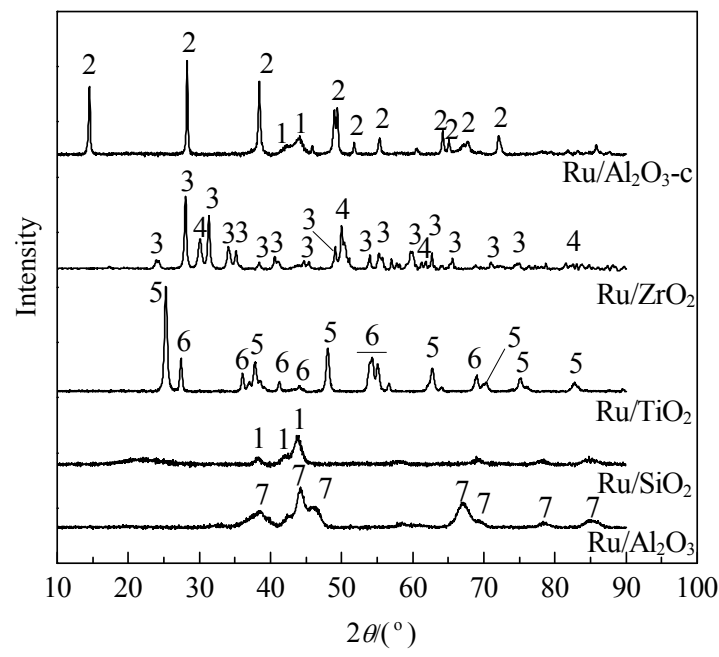

Fig. 2. XRD patterns of the supported Ru catalysts with the attribution. 1, $\mathrm{Ru}^{0} ; 2$, $\mathrm{AlOOH} ; 3, \mathrm{ZrO}_{2}$ monoclinic; $4, \mathrm{ZrO}_{2}$ tetragonal; $5, \mathrm{TiO}_{2}$ anatase; $6, \mathrm{TiO}_{2}$ rutile; $7, \mathrm{Al}_{2} \mathrm{O}_{3}$.

diffractogram exhibited narrower and more intense peaks which were attributed to the boehmite phase (JCPDS 5-0190) indicating a better crystallized structure compared to the more amorphous aluminum oxide structure observed for $\mathrm{Ru} / \mathrm{Al}_{2} \mathrm{O}_{3}$. The Ru crystallites sizes for the $\mathrm{Ru} / \mathrm{SiO}_{2}$ and $\mathrm{Ru} / \mathrm{Al}_{2} \mathrm{O}_{3}-\mathrm{c}$ samples were calculated by Scherrer equation to the diffraction line at $2 \theta=44^{\circ}$, and were 8.3 and $8.0 \mathrm{~nm}$, respectively. The absence of diffraction lines from Ru prevented the estimate of the $\mathrm{Ru}$ particle size by XRD for the other catalysts.

TEM characterization was conducted to estimate the Ru particle size in all the catalysts. Representative TEM images of the supported Ru catalysts are shown in Fig 3, and the histograms of the Ru particle size distribution are also included. Around 200 particles were used to establish the distribution of particle sizes for each sample. The $\mathrm{Ru} / \mathrm{Al}_{2} \mathrm{O}_{3}$ catalyst presented a narrow particle size distribution with an average size of 3.7 $\mathrm{nm}$. Similar homogeneous distributions of Ru particles with an average particle size of 3.8 and $2.7 \mathrm{~nm}$, respectively, were observed for the $\mathrm{Ru} / \mathrm{TiO}_{2}$ and $\mathrm{Ru} / \mathrm{ZrO}_{2}$ catalysts. In the case of the $\mathrm{Ru} / \mathrm{SiO}_{2}$ catalyst, the particle size was larger than $9 \mathrm{~nm}$ and had a wider distribution. These results confirmed the XRD data, that is, the $\mathrm{Ru} / \mathrm{SiO}_{2}$ catalyst had larger and less dispersed $\mathrm{Ru}$ particles than the other catalysts.

$\mathrm{H}_{2}$ chemisorption measurements were also conducted. The irreversible $\mathrm{H}_{2}$ uptake, amount of Ru atoms exposed at the surface, estimated particle size and derived Ru dispersion are
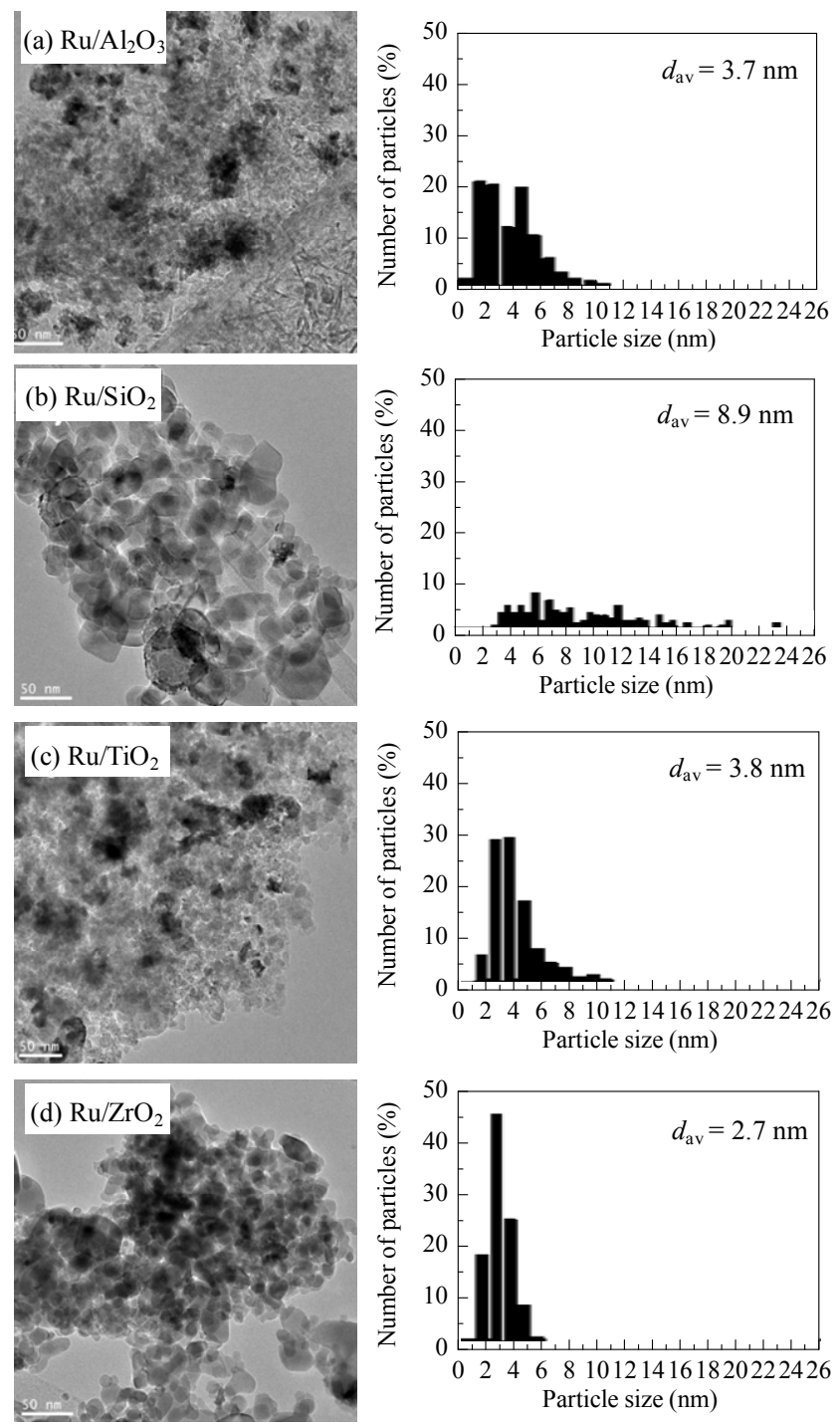

Fig. 3. TEM micrographs and histograms of the Ru particle size distribution for the supported Ru catalysts.

compiled in Table 2. In the case of the RuSi catalyst, the dispersion could not be determined due to the negligible amount of $\mathrm{H}_{2}$ uptake at $373 \mathrm{~K}$. The same behavior has been previously reported in the range of 303-523 $\mathrm{K}$ by other authors [35]. In general, the chemisorption was performed appropriately at $373 \mathrm{~K}$. However for the $\mathrm{Ru} / \mathrm{TiO}_{2}$ catalyst, the chemisorption was carried out at $333 \mathrm{~K}$ to avoid the hydrogen spillover effect from $\mathrm{Ru}$ to the support because this effect is accentuated at

Table 2

Irreversible $\mathrm{H}_{2}$ uptake determined by $\mathrm{H}_{2}$ chemisorption and $\mathrm{Ru}$ average particle size by different techniques for the supported Ru catalysts.

\begin{tabular}{|c|c|c|c|c|c|c|c|}
\hline \multirow{2}{*}{ Catalyst } & \multicolumn{5}{|c|}{$\mathrm{H}_{2}$ chemisorption } & \multicolumn{2}{|c|}{ Size $(\mathrm{nm})$} \\
\hline & $T / \mathrm{K}$ & Irrev. $\mathrm{H}_{2}$ uptake $\left(\mu \mathrm{mol} \mathrm{H} / \mathrm{H}_{\text {cat. }}\right)$ & $\mathrm{Ru}$ exposed $\left(\mu \mathrm{mol} \mathrm{Ru} / \mathrm{g}_{\text {cat. }}\right)$ & $D_{\mathrm{Ru}}(\%)$ & Size $(\mathrm{nm})$ & TEM & XRD \\
\hline $\mathrm{Ru} / \mathrm{Al}_{2} \mathrm{O}_{3}$ & 373 & 71 & 141 & 29 & 3.2 & 3.7 & $-\mathrm{a}$ \\
\hline $\mathrm{Ru} / \mathrm{SiO}_{2}$ & 373 & $\approx 0$ & n.d. & n.d & n.d & 8.9 & 8.3 \\
\hline $\mathrm{Ru} / \mathrm{TiO}_{2}$ & 333 & 62 & 125 & 25 & 3.7 & 3.8 & $-{ }^{a}$ \\
\hline $\mathrm{Ru} / \mathrm{ZrO}_{2}$ & 373 & 148 & 297 & 60 & 1.5 & 2.7 & $-\mathrm{a}$ \\
\hline
\end{tabular}

${ }^{a}$ No diffraction peaks of Ru could be clearly identified.

n.d.: not determined. 
high temperature. $\mathrm{Ru} / \mathrm{Al}_{2} \mathrm{O}_{3}$ has a $\mathrm{Ru}$ dispersion of $29 \%$ which corresponded to a mean particle size of $3.2 \mathrm{~nm}$. $\mathrm{Ru} / \mathrm{ZrO}_{2}$ showed a higher dispersion of $60 \%$ to give an average particle size of $1.5 \mathrm{~nm}$.

Table 2 also compiled the particle size estimated by XRD, TEM, and $\mathrm{H}_{2}$ chemisorption. It was possible to estimate the $\mathrm{Ru}$ particle size by TEM for all the catalysts. The mean particle size followed the order: $\mathrm{Ru} / \mathrm{ZrO}_{2}<\mathrm{Ru} / \mathrm{Al}_{2} \mathrm{O}_{3} \approx \mathrm{Ru} / \mathrm{TiO}_{2}<<\mathrm{Ru} / \mathrm{SiO}_{2}$. Except $\mathrm{Ru} / \mathrm{SiO}_{2}$ catalyst, the estimated particle sizes of other catalysts by TEM and $\mathrm{H}_{2}$ chemisorption were within the same size range

XPS studies were carried out for the supported Ru catalysts to identify the oxidation state of the Ru species present on the catalyst surface and their surface $\mathrm{Ru} / \mathrm{X}$ atomic ratio. Figure 4 shows the XPS spectra of the $\mathrm{Ru} 3 d$ region for the $\mathrm{Ru} / \mathrm{Al}_{2} \mathrm{O}_{3}$, $\mathrm{Ru} / \mathrm{SiO}_{2}, \mathrm{Ru} / \mathrm{TiO}_{2}$, and $\mathrm{Ru} / \mathrm{ZrO}_{2}$ catalysts. In all of these, there was a component between 279-283 eV corresponding to the $\mathrm{Ru} 3 d_{5 / 2}$ core level and a $\mathrm{Ru} 3 d_{3 / 2}$ contribution at $4.1 \mathrm{eV}$ higher $\mathrm{BE}$ which overlapped with the $\mathrm{C} 1 \mathrm{~s}$ region. Due to this overlapping, the $C$ peak was not used as reference and the metal of the catalyst support was used as reference. The $\mathrm{Ru} / \mathrm{Al}_{2} \mathrm{O}_{3}$ catalyst presented two peaks in the $\mathrm{Ru} 3 d_{5 / 2}$ region: one centered at $280.6 \mathrm{eV}$ corresponding to the $\mathrm{Ru}^{0}$ species and a second contribution at $282.4 \mathrm{eV}$ which was associated with the $\mathrm{Ru}^{\delta+}$ species in $\mathrm{RuO}_{x}$ [33,36-38]. The intensity of the latter was slightly less. The presence of $\mathrm{Ru}^{\delta+}$ species on the surface cannot be associated with reoxidation during the transfer to the XPS chamber because after the reduction the catalysts were protected from contact with the ambient atmosphere. As will be seen later, the presence of $\mathrm{Ru}^{\delta+}$ in this catalyst can be associated with the interaction of $\mathrm{Ru}$ species with acid centers of moderate strength present on the surface of the $\mathrm{Al}_{2} \mathrm{O}_{3}$ support, which was not reduced in the activation process. The $\mathrm{Ru} / \mathrm{SiO}_{2}$ catalyst presented a single peak in the $\mathrm{Ru} 3 d_{5 / 2}$ region, which was centered at $280.1 \mathrm{eV}$ and assigned to $\mathrm{Ru}$ in the metallic state. For the $\mathrm{Ru} / \mathrm{TiO}_{2}$ catalyst, two less intense contributions were de-

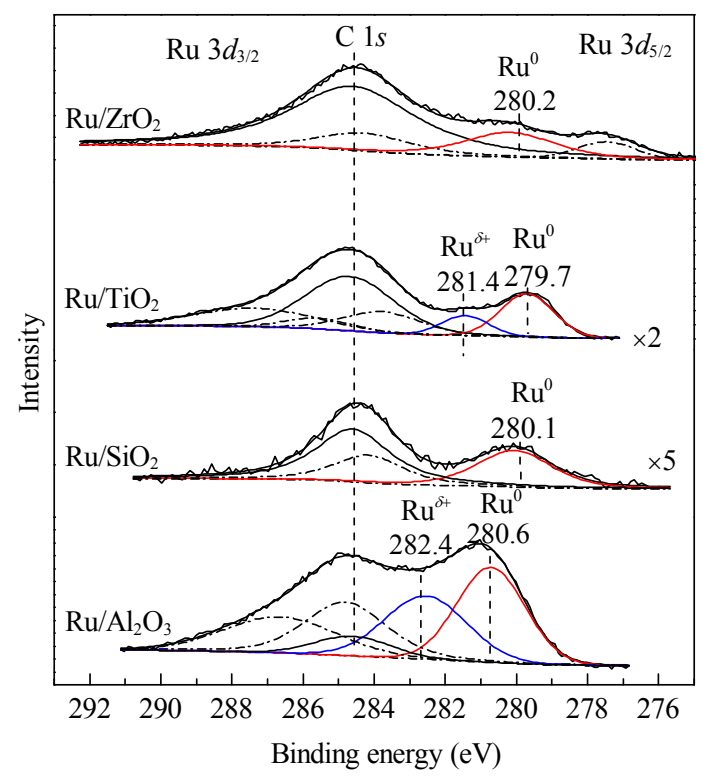

Fig. 4. Ru $3 d$ XPS spectra obtained for the supported Ru catalysts.
Table 3

$\mathrm{Ru} 3 d_{5 / 2}$ binding energies and $\mathrm{Ru} / \mathrm{X}$ atomic ratios derived from XPS data for the supported Ru catalysts.

\begin{tabular}{lccc}
\hline Catalyst & $\mathrm{BE} \mathrm{ref}(\mathrm{eV})$ & $\mathrm{Ru} 3 d_{5 / 2^{\mathrm{a}}(\mathrm{eV})}$ & $\mathrm{Ru} / \mathrm{X}^{\mathrm{b}}$ \\
\hline $\mathrm{Ru} / \mathrm{Al}_{2} \mathrm{O}_{3}$ & $\mathrm{Al} 2 p(74.5)$ & $280.6(55), 282.4(45)$ & 0.15 \\
$\mathrm{Ru} / \mathrm{SiO}_{2}$ & $\mathrm{Si} 2 p(103.4)$ & 280.1 & 0.01 \\
$\mathrm{Ru} / \mathrm{TiO}_{2}$ & $\mathrm{Ti} 2 p(458.5)$ & $279.7(70), 281.4(30)$ & 0.06 \\
$\mathrm{Ru} / \mathrm{ZrO}_{2}$ & $\mathrm{Zr} 3 d(182.1)$ & 280.2 & 0.05 \\
\hline
\end{tabular}

aVlues in brackets refer to the percentage.

${ }^{\mathrm{b}} \mathrm{X}$ refers to the metallic atom on the support oxide.

tected at 279.7 and $281.4 \mathrm{eV}$, which were attributed to the $\mathrm{Ru}^{0}$ and $\mathrm{Ru}^{\delta+}$ species, respectively. $\mathrm{Ru} / \mathrm{ZrO}_{2}$ displayed only a peak for $\mathrm{Ru} 3 d_{5 / 2}$ at $280.2 \mathrm{eV}$ corresponding to metallic $\mathrm{Ru}$, and the contribution from $\mathrm{Ru}^{\delta+}$ species was not observed as was also the case with the $\mathrm{Ru} / \mathrm{SiO}_{2}$ catalyst. The peak $277.4 \mathrm{eV}$ could not be unambiguously assigned but it was not due to $\mathrm{Ru}$ species because the binding energy was very low.

Table 3 compiles the parameters deduced from the XPS study. $\mathrm{Ru} / \mathrm{Al}_{2} \mathrm{O}_{3}$ clearly presented a high proportion of $\mathrm{Ru}^{\delta+}$ species (45\%) as compared with the $\mathrm{Ru} / \mathrm{TiO}_{2}$ catalyst (30\%). For $\mathrm{Ru} / \mathrm{SiO}_{2}$ and $\mathrm{Ru} / \mathrm{ZrO}_{2}$, uniquely metallic $\mathrm{Ru}$ species were observed. The $\mathrm{Ru} / \mathrm{X}$ atomic ratios (where $\mathrm{X}$ is the metal used in the support for each catalyst) were also collected in the Table 3. The $\mathrm{Ru}$ supported on $\mathrm{Al}_{2} \mathrm{O}_{3}$ presented the largest atomic ratio $(\mathrm{Ru} / \mathrm{Al}=0.15)$. The XPS atomic ratio was smaller for the $\mathrm{Ru} / \mathrm{TiO}_{2}$ and $\mathrm{Ru} / \mathrm{ZrO}_{2}$ catalysts $(\mathrm{Ru} / \mathrm{Ti}=0.06$ and $\mathrm{Ru} / \mathrm{Zr}=$ 0.05). The $\mathrm{Ru} / \mathrm{SiO}_{2}$ catalyst showed the lowest atomic ratio with a value of $\mathrm{Ru} / \mathrm{Si}=0.01$. Two relevant conclusions regarding the $\mathrm{Ru} / \mathrm{Al}_{2} \mathrm{O}_{3}$ catalyst can be drawn: first, a large fraction of the surface $\mathrm{Ru}$ atoms were partially oxidized, and second, the $\mathrm{Ru}$ surface concentration was higher than that found for the other catalysts.

To examine further the formation of partially oxidized $\mathrm{Ru}$ species on the surface of $\mathrm{Ru} / \mathrm{Al}_{2} \mathrm{O}_{3}$, the surface acidity of the supported $\mathrm{Ru}$ catalysts was evaluated by $\mathrm{NH}_{3}$-TPD. During TPD experiments the reduction of the catalysts by ammonia can be discarded since associated fragments to nitrogen oxide compounds have not been detected. Figure 5 displays the $\mathrm{NH}_{3}$-TPD profiles of the supported $\mathrm{Ru}$ catalysts. The profile of the $\mathrm{Al}_{2} \mathrm{O}_{3}$ support is also displayed as a reference. It was clearly observed

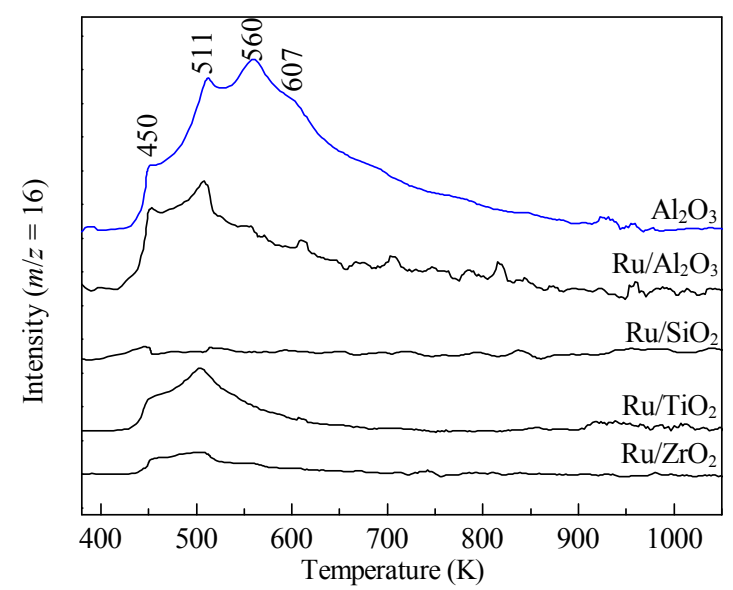

Fig. 5. $\mathrm{NH}_{3}$-TPD profiles of the supported Ru catalysts. 
that the $\mathrm{NH}_{3}$ desorption from the $\mathrm{Al}_{2} \mathrm{O}_{3}$ support gave the peaks at 560 and $607 \mathrm{~K}$, which have been suppresed with the supported Ru catalyst. This suppression indicated that the strongest acid sites of the $\mathrm{Al}_{2} \mathrm{O}_{3}$ surface have dissappeared. This behavior has been previously reported [35,39] and it was attributed to the strong interaction between the Ru particles and the acid centers with the strongest acidity of the $\mathrm{Al}_{2} \mathrm{O}_{3}$ support. This interaction generated the partially oxidized $\mathrm{Ru}$ species on the surface seen in the XPS analysis. For the $\mathrm{Ru} / \mathrm{TiO}_{2}$ and $\mathrm{Ru} / \mathrm{ZrO}_{2}$ catalysts, this phenomenon could also occur, but to a lesser extent.

The quantification of the weak acidity (400-550 K range) for the supported Ru catalysts showed that the number of acid sites was the highest for $\mathrm{Ru} / \mathrm{Al}_{2} \mathrm{O}_{3}\left(38 \mu \mathrm{mol} \mathrm{NH} / 3 / \mathrm{g}_{\text {cat }}\right)$, while the $\mathrm{Ru} / \mathrm{SiO}_{2}$ catalyst showed a flat desorption profile, that is, its surface acidity was practically negligible. The $\mathrm{Ru} / \mathrm{TiO}_{2}$ and $\mathrm{Ru} / \mathrm{ZrO}_{2}$ catalysts presented desorption peaks with medium intensity at temperatures in the range of 400-550 K, representing the desorption of 19 and $7 \mu \mathrm{mol} \mathrm{NH} / 3 / \mathrm{g}_{\text {cat, }}$, respectively.

\subsection{Role of surface species on the catalytic performance}

The use of different supports changed the physicochemical properties of the Ru particles and allowed more Ru to be exposed to facilate the interaction with adsorbed sorbitol. For the dispersion of $\mathrm{Ru}$, it must be kept in mind that with $\mathrm{H}_{2}$ chemisorption, only Ru in the metallic state can be titrated. A fraction of the Ru was partially oxidized $\left(\mathrm{Ru}^{\delta+}\right)$ that was present on the surface of $\mathrm{Ru} / \mathrm{TiO}_{2}$ and especially the $\mathrm{Ru} / \mathrm{Al}_{2} \mathrm{O}_{3}$ catalyst. Thus the dispersion of $\mathrm{Ru}$ was understimated for $\mathrm{Ru} / \mathrm{TiO}_{2}$ and $\mathrm{Ru} / \mathrm{Al}_{2} \mathrm{O}_{3}$. With taking this into account, it can be concluded that the $\mathrm{Ru} / \mathrm{ZrO}_{2}$ catalyst has the highest metal dirpersion and consequently the smallest particle size, closely followed by the $\mathrm{Ru} / \mathrm{Al}_{2} \mathrm{O}_{3}$ and $\mathrm{Ru} / \mathrm{TiO}_{2}$ catalysts. If one assumes that sorbitol hydrogenolysis to produce glycerol, 1,2-PG and EG needs C-C and C- 0 scission sites $[14,19,20,22,23]$, metallic sites are required and a larger amount of exposed Ru atoms is beneficial. However, according to the values obtained for the different catalysts in this work, there was no clear correlation between sorbitol conversion and the particle size of Ru, at least, in the range of particle size smaller than $9 \mathrm{~nm}$.

Concerning the oxidation state of $\mathrm{Ru}$ on the surface, the $\mathrm{Ru} / \mathrm{ZrO}_{2}$ and $\mathrm{Ru} / \mathrm{SiO}_{2}$ catalysts only presented $\mathrm{Ru}$ in the metallic state while some $\mathrm{Ru}^{\delta+}$ was detected in $\mathrm{Ru} / \mathrm{Al}_{2} \mathrm{O}_{3}$ and $\mathrm{Ru} / \mathrm{TiO}_{2}$. The presence of $\mathrm{Ru}^{\delta+}$ was due to the interaction of small $\mathrm{Ru}$ particles with acid sites. Although both the $\mathrm{Ru} / \mathrm{Al}_{2} \mathrm{O}_{3}$ and $\mathrm{Ru} / \mathrm{TiO}_{2}$ catalysts have $\mathrm{Ru}^{\delta+}$ species on the surface, however, there were significant differences between the two catalysts, which may explain their different catalytic behavior. The binding energy of the $\mathrm{Ru}^{\delta+}$ species on the surface of the $\mathrm{Ru} / \mathrm{TiO}_{2}$ catalyst was $1 \mathrm{eV}$ lower than for $\mathrm{Ru} / \mathrm{Al}_{2} \mathrm{O}_{3}$, suggesting that the interaction of $\mathrm{Ru}$ particles with $\mathrm{Al}_{2} \mathrm{O}_{3}$ was stronger resulting in more transfer of charge from the Ru particles to the support and consequently a higher oxidation state for the $\mathrm{Ru}$ atoms. Besides the $\mathrm{Ru} / \mathrm{TiO}_{2}$ catalyst has a lower proportion of $\mathrm{Ru}^{\delta+}$ on the surface compared to the $\mathrm{Ru} / \mathrm{Al}_{2} \mathrm{O}_{3}$ sample: the XPS $\mathrm{Ru} / \mathrm{TiO}_{2}$ ratio was smaller than the $\mathrm{XPS} \mathrm{Ru} / \mathrm{Al}_{2} \mathrm{O}_{3}$ ratio and the
XPS spectrum was much less intense (spectrum was multiplied by 2 , see Fig. 4). In summary the surface concentration of $\mathrm{Ru}^{\delta+}$ on the $\mathrm{Ru} / \mathrm{Al}_{2} \mathrm{O}_{3}$ catalyst was larger than on the $\mathrm{Ru} / \mathrm{TiO}_{2}$ sample, and therefore so was the effect of $\mathrm{Ru}^{\delta+}$.

Another significant difference between the $\mathrm{Ru} / \mathrm{Al}_{2} \mathrm{O}_{3}$ and the other catalysts was the concentration of acid sites measured by $\mathrm{NH}_{3}$-TPD, being $38 \mu \mathrm{mol} \mathrm{NH}_{3} / \mathrm{g}_{\text {cat }}$ for $\mathrm{Ru} / \mathrm{Al}_{2} \mathrm{O}_{3}$ while the $\mathrm{Ru} / \mathrm{TiO}_{2}$ catalyst has $19 \mu \mathrm{mol} \mathrm{NH} / \mathrm{g}_{\text {cat }}$ and these were well above those of $\mathrm{Ru} / \mathrm{ZrO}_{2}$ and $\mathrm{Ru} / \mathrm{SiO}_{2}$ catalysts. Therefore, it would seem that the surface concentration of acid sites was also relevant for glycerol dehydration to produce glycols (1,2-PG and EG).

In summary, an explanation for the higher selectivity and yield to glycols with the $\mathrm{Ru} / \mathrm{Al}_{2} \mathrm{O}_{3}$ catalyst may be that the $\mathrm{Al}_{2} \mathrm{O}_{3}$ promoted the dehydrogenation rate of sorbitol due to the presence of acid sites as was recently proposed for $\mathrm{Ni} / \mathrm{Al}_{2} \mathrm{O}_{3}$ catalysts [17]. Once the retro-aldol condensation step occurred, the higher acidity of the $\mathrm{Ru} / \mathrm{Al}_{2} \mathrm{O}_{3}$ catalyst allowed glycerol dehydration and subsequent hydrogenation to give glycols selectively. More study is needed to understand the specific role of the presence of $\mathrm{Ru}^{\delta+}$ on the dehydrogenation rate of sorbitol and the acidic surface in the reaction mechanism and its relevance to the yield and selectivity to glycols.

\section{Conclusions}

The support has an effect on the physicochemical properties of supported $\mathrm{Ru}$ catalysts and their catalytic activity. The $\mathrm{Ru} / \mathrm{Al}_{2} \mathrm{O}_{3}$ catalyst prepared by impregnation showed the highest selectivity and yield to glycols. Under the reaction conditions used ( $493 \mathrm{~K}, 4 \mathrm{MPa}$ of $\mathrm{H}_{2}$ and without basic promoter), the surface concentration of both acid sites and partially oxidized $\mathrm{Ru}$ species were relevant properties that gave a high selectivity to glycols. The Ru dispersion was less important for determining the catalytic performance.

\section{Acknowledgements}

Financial support from Spanish Ministry of Economy and Competitiveness (CTQ2012-38204-C03-01) is gratefully acknowledged. I.M.L. thanks to CSIC (JAE-Predoctoral grant) for her financial support.

\section{References}

[1] Wettstein S G, Alonso D M, Gürbüz E I, Dumesic J A. Curr Opin Chem Eng, 2012, 1: 218

[2] Adsul M G, Singhvi M S, Gaikaiwari S A, Gokhale D V. Bioresource Technol, 2011, 102: 4304

[3] Zhu J Y, Zhuang X S. Prog Energ Combust, 2012, 38: 583

[4] Dautzenberg G, Gerhardt M, Kamm B. Holzforschung, 2011, 65 : 439

[5] Wang A, Zhang T. Accounts Chem Res, 2013, 46: 1377

[6] Ji N, Zhang T, Zheng M, Wang A, Wang H, Wang X, Chen J G. Angew Chem Int Ed, 2008, 47: 8510

[7] Baek I G, You S J, Park E D. Bioresource Technol, 2012, 114: 684

[8] Liu M, Wang H, Han J, Niu Y. Carbohyd Polym, 2012, 89: 607

[9] Han J W, Lee H. Catal Commun, 2012, 19: 115 


\section{Graphical Abstract}

Chin. J. Catal., 2014, 35: 614-621 doi: 10.1016/S1872-2067(14)60086-3

\section{Sorbitol hydrogenolysis to glycols by supported ruthenium catalysts}

Inmaculada Murillo Leo, Manuel Lopez Granados, Jose Luis Garcia Fierro, Rafael Mariscal* Institute of Catalysis and Petrochemistry (CSIC), Spain

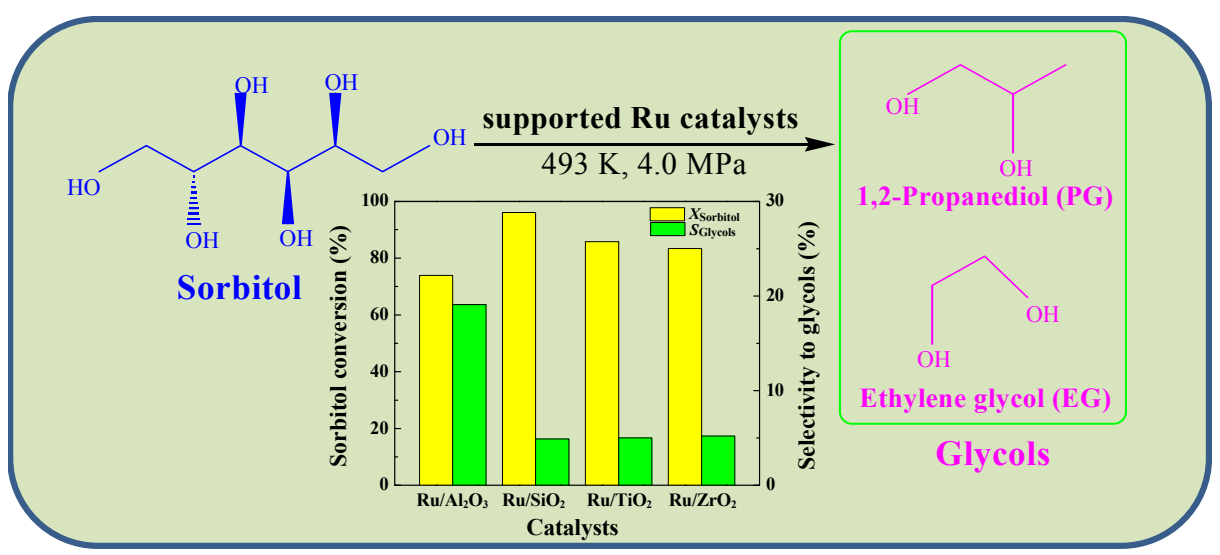

$\mathrm{A} \mathrm{Ru} / \mathrm{Al}_{2} \mathrm{O}_{3}$ catalyst prepared by impregnation showed the highest selectivity and yield to glycols because it is had the most acid sites and partially oxidized Ru species.

[10] Fukuoka A, Dhepe P L. Angew Chem Int Ed, 2006, 45: 5161

[11] Ji N, Zhang T, Zheng M, Wang A, Wang H, Wang X, Shu Y, Stottlemyer A L, Chen J G. Catal Today, 2009, 147: 77

[12] Bozell J J, Petersen G R. Green Chem, 2010, 12: 539

[13] Sun J, Liu H. Green Chem, 2011, 13: 135

[14] Banu M, Venuvanalingam P, Shanmugam R, Viswanathan B, Sivasanker S. Top Catal, 2012, 55: 897

[15] Li N, Huber G W.J Catal, 2010, 270: 48

[16] Chen X, Wang X, Yao S, Mu X. Catal Commun, 2013, 39: 86

[17] Liang G, He L, Cheng H, Li W, Li X, Zhang C, Yu Y, Zhao F. J Catal, 2014, 309: 468

[18] Deutsch K L, Lahr D G, Shanks B H. Green Chem, 2012, 14: 1635

[19] Sohounloue D K, Montassier C, Barbier J. React Kinet Catal Lett, 1983, 22: 391

[20] Zhao L, Zhou J, Chen H, Zhang M, Sui Z, Zhou X. Korean J Chem Eng, 2010, 27: 1412

[21] Zhou J H, Zhang M G, Zhao L, Li P, Zhou X G, Yuan W K. Catal Today, 2009, 147: S225

[22] Zhao L, Zhou J H, Sui Z J, Zhou X G. Chem Eng Sci, 2010, 65: 30

[23] Banu M, Sivasanker S, Sankaranarayanan T M, Venuvanalingam P. Catal Commun, 2011, 12: 673

[24] Ye L, Duan X, Lin H, Yuan Y. Catal Today, 2012, 183: 65

[25] Soták T, Schmidt T, Hronec M. Appl Catal A, 2013, 459: 26

[26] Lin H Y, Chen Y W. Thermochim Acta, 2004, 419: 283
[27] Shen X, Garces L J, Ding Y, Laubernds K, Zerger R P, Aindow M, Neth E J, Suib S L. Appl Catal A, 2008, 335: 187

[28] Okal J, Zawadzki M, Kepinski L, Krajczyk L, Tylus W. Appl Catal A, 2007, 319: 202

[29] Wagner C D, Davis L E, Zeller M V, Taylor J A, Raymond R H, Gale L H. Surf Interface Anal, 1981, 3: 211

[30] Yamaguchi A, Hiyoshi N, Sato O, Shirai M. Green Chem, 2011, 13: 873

[31] Vilcocq L, Cabiac A, Especel C, Lacombe S, Duprez D. Catal Today, 2012, 189: 117

[32] Xia J, Yu D, Hu Y, Zou B, Sun P, Li H, Huang H. Catal Commun, 2011, 12: 544

[33] Mazzieri V, Coloma-Pascual F, Arcoya A, L'Argentière P C, Fígoli N S. Appl Surf Sci, 2003, 210: 222

[34] Choque V, de la Piscina P R, Molyneux D, Homs N. Catal Today, 2010, 149: 248

[35] Vasiliadou E S, Heracleous E, Vasalos I A, Lemonidou A A. Appl Catal B, 2009, 92: 90

[36] Cattania M G, Parmigiani F, Ragaini V. Surf Sci, 1989, 211-212: 1097

[37] Chan H Y H, Takoudis C G, Weaver M J. J Catal, 1997, 172: 336

[38] Hengne A M, Biradar N S, Rode C V. Catal Lett, 2012, 142: 779

[39] Liao X, Li K, Xiang X, Wang S G, She X, Zhu Y, Li Y. J Ind Eng Chem, 2012, 18: 818 